\title{
Disasters: contributions of hazardscape and gaps in response practices
}

\author{
S. $\operatorname{Khan}^{1, *}$ \\ ${ }^{1}$ New Zealand Climate Change Research Institute, Victoria University of Wellington, P.O. Box 600, Wellington, New Zealand \\ * currently at: Department of Geography, Delhi School of Economics, University of Delhi, New Delhi-110007, India
}

Correspondence to: S. Khan (shabana.khan@hotmail.co.nz)

Received: 14 May 2011 - Revised: 28 October 2012 - Accepted: 10 November 2012 - Published: 21 December 2012

\begin{abstract}
Disasters are frequent, ongoing and very likely to increase in the future with global climate change. Significant investments in hazard mitigation, policies and emergency management have so far failed to stop disasters. Their recurrences suggest that either there are some gaps in the current response or a different perspective is needed on the way hazards have been dealt with to date. This paper views disasters through the lens of hazardscape, which shows the context of both hazard occurrence and response. It finds that one major cause of response failure is inadequate consideration of the local hazardscape in planning. It notes that although globalization of hazard response practices is progressive, it has been less successful in dealing with local variations in vulnerability. This paper presents the conceptual framework of hazardscape, and illustrates various shortcomings of the current responses in relation to the local hazardscapes where they are adopted. It recommends a holistic approach that considers various aspect of the hazardscape in order to plan a response strategy.
\end{abstract}

\section{Introduction}

The frequency, intensity and scale of the recent disasters point towards staggering risks widespread in the world. In the 5129 recorded natural disasters from 2000 to 2011, over 1.17 million people were killed, 3.96 million were injured, 30.9 million became homeless, 2.6 billion affected, and an economic damage of about USD 1.3 trillion occurred in both developed and developing countries (CRED, 2012, 8 April 2012). Substantial damages from earthquakes occurred not only in the less prepared countries, such as Haiti (2010), Pakistan (2005) or India (2001), but also in the world's most prepared nations, such as Japan (2011) and New Zealand (2011) (World News Atlas, 2011). Storms led disasters in both rich and poor countries, be it USA (Hurricane Katrina in 2005) or Myanmar (Cyclone Nargis in 2008) (UNISDR, 2009b). The Indian Ocean Tsunami alone caused 226408 fatalities and ruined infrastructure in at least 12 countries irrespective of their level of development (UNISDR, 2009b; BBC, 22 December 2005). Disaster recurrences not only challenge the "superiority of planning" but also the economic growth in dealing with their root causes (Wisner, 2011).

This paper brings forth a conceptual framework of the hazardscape in order to highlight some of the reasons behind recurrent disasters and response failures. The term "response" is frequently referred to as the immediate response to a disaster or emergency (UNISDR, 2009a). However, in this paper, the word response is used as an umbrella term which includes all actions or no action taken by the people, communities or institutions to deal with natural hazards or disasters (Burton et al., 1993). The paper critically analyses the effectiveness of some of the common mitigation measures and emergency response practices applied in different hazardscapes. It is an afterward of a $\mathrm{PhD}$ dissertation entitled as "A geographical assessment of the hazardscape of the Wellington Region: Influences on intra-regional response" and a forward that brings examples from different nations to evaluate response gaps. Apart from the secondary data and literature on hazards, risk and disaster response, a few findings of this paper are also supported by the interviews conducted to assess local response to various hazards with the civil defence officers and resource planners from the eight city and district councils of the Wellington Region, New Zealand. 


\section{Hazardscape: a conceptual framework}

A range of theories have been developed that view hazards and disasters from different perspectives. Starting from the behavioural models of hazards based on the human adjustments to environment (Ericksen, 1986; Smith, 1992; Burton et al., 1978) to the studies looking at vulnerability and focusing on weaknesses in the human systems (Bohle, 2001; Wisner et al., 2004) a momentous shift in approach is specified. The assessment of sustainability (Turner II et al., 2003), resilience (Paton, 2006), ecosystem (Mileti, 1999) and place vulnerability (Cutter et al., 2000) further add to these perspectives. Although most of these theories provide significant insight into hazards and disasters, they are loosely connected and present a partial view of reality depending on their focus of attention. Therefore, a new framework is sought for a holistic approach that explains various aspects of hazards, risks and disasters at a place. The theory of hazardscape presented here, although not exhaustive, is a step towards bringing together different concepts and phenomena relating to hazards and response, and assessing them in relation to each other.

In the recent past, three similar terms - hazardscape, riskscape and disasterscape - have been used interchangeably in the literature (Corson, 1999; Cutter et al., 2000; Gray, 2001; Mustafa, 2005; ODESC, 2007; Kapur, 2010). This research acknowledges that the three terms are related but finds them conceptually distinct and therefore have different methodologies for assessment and planning. While a hazardscape represents the existing and potential sources of threats (hazards), riskscape portrays potential damage (risks) and disasterscape demonstrates the actual damage (disasters) (Fig. 1) (Reese et al., 2007; Kapur, 2010). Hazardscape is chosen for the study, as it provides an opportunity to intervene risk accumulation and avoid disasters.

The term "hazardscape" was first defined by Corson in 1999. With a focus on technological hazards, he defined hazardscape as "the spatial distribution and attributes of human engineered facilities... that contain or emit substances harmful to humans and environment" (Corson, 1999). Even though this definition is relevant to most technological hazards, it does not fully apply to hazards in general or to natural hazards. In the following year, Cutter et al. (2000) used the word "hazardscape" interchangeably with "riskscape" but they did not define the term. Gray (2001) used the word hazardscape to describe the collective areas of risks associated with hazards. This definition again interpreted the hazardscape in terms of risk rather than specifying its source. Mustafa (2005) described hazardscape as an integrative concept, and defined it as "both an analytical way of seeing that asserts power, and as a social-environmental space where the gaze of power is contested and struggled against to produce a lived reality of a hazardous place". He used the term hazardscape as a substitute for natural hazards, which denotes some external nature as the key causative element in the hazardousness and vulnerability of life (Mustafa, 2005). In this definition, the author rightly suggests that the hazardscape is an integrative concept, but later concedes external nature as the prime cause of hazards and vulnerability. Therefore, an attempt is made for a more inclusive definition.

A hazardscape neither just simply refers to the hazards of a place nor indicates them to be caused by some external factors in the environment. Rather, it demonstrates the ecological perspective of hazards and consequent risks, which build through intricate relationships between human beings and the environment in a particular spatio-temporal context. It represents process behaviours along with place and people's characteristics that favour hazard occurrence. The definition of hazard as "an agent (event, process or situation), which can cause damage to life and property" (Glade et al., 2005), implies that hazards exist not only because of unstable characteristics of environmental processes (when it says agent or process), but are also due to the physical susceptibility of the place (i.e. situation, which implies place characteristics) and human vulnerability (relating to damage to life and property). Physical susceptibility here characterizes the likelihood of a place to experience natural hazards due to its biophysical characteristics, while human vulnerability in its simplest form refers to the liability of a community or people to experience damage from hazards at a given place (Smith, 1992). Hazards, physical susceptibility and vulnerability change through time and give a dynamic character to a hazardscape. A hazardscape is therefore defined here as "a dynamic scape which reflects the physical susceptibility of a place and vulnerability of human life and assets to various hazards in a given human ecological system".

\subsection{The context and characteristics of a hazardscape}

\subsubsection{The context}

Ecosystems provide the context in which a hazardscape exists. An ecosystem is the foundation concept of ecology, but it has been used in a different sense in human ecology. Tansley, who founded the concept, defined ecosystems "in the sense of physics, including not only the organism complex, but also the whole complex of physical factors forming what we call the environment of the biome - the habitat factors in widest sense" (Tansley, 1935, p. 299). Hawley, who wrote a detailed theoretical essay of human ecology, defined ecosystem as "an arrangement of mutual dependence in a population by which the whole operates as a unit and thereby maintains a viable environmental relationship" (Hawley, 1986, p. 26). His concept of ecosystem basically explains a system without "environment or eco", which is simply a population system. This conception of ecosystem, which was shared by many sociologists of the time, disqualified many ecological principles, which were otherwise applicable to other living beings in their ecosystems (Catton, 1994, p. 78). The 


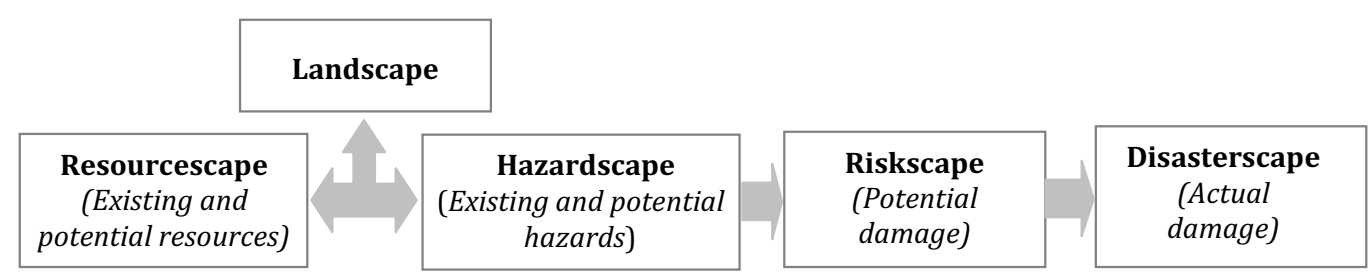

Fig. 1. Relationship between hazardscape, riskscape and disasterscape.

omission of the environment from the ecosystem led human ecology to view humans and environment as separate entities having their separate systems, which despite influencing each other, are not related. The notion of humans and environment as separate systems also exists in hazard theories, which has long directed scientists to find solutions through modification and suppression of natural processes that reduced the likelihood of minor frequent events but increased the risk of extreme events (Tobin and Montz, 1997).

This leads to the meaning and definition of environment, which has also been contested between natural and social scientists (Barry, 2007, p. 12). In early hazard research "nature" is frequently used as synonymous with "environment" (see Kates, 1971, p. 438; Burton et al., 1978), which basically referred to the biophysical world as being separate from human beings and to which humans adapt or exploit for resources. In contrast, sociologists view environment as predominantly human - encompassing society, culture, economy, politics, technology and built infrastructure where nature plays a little role (Hawley, 1986). Both definitions are valid in the sense that they apply the literal meaning of the term environment, which means to surround the object in focus, nevertheless they view environment only partially. For hazard analysis, it is important to consider both views as they project different roles that the environment could play in hazard creation. While the physical environment determines the physical susceptibility of the place, the human environment dominantly influences vulnerability, and together they not only govern the intensity of different hazards but also the response of the community. This relationship defines the core of the concept of "hazardscape".

Various aspects of ecosystems including space, process, connectivity, change, uncertainty and scale help to understand the origin, development and complexity of hazardscapes (Wessels, 2006). Space is the basic requirement for any ecosystem to exist and operate, and a hazardscape develops in a three dimensional space within an ecosystem as human life has evolved in the ecosystem rather than in a vacuum. A hazardscape therefore, reflects most processes and associated changes operating in the ecosystem, which shape its various characteristics. Further, since most of the processes are interconnected and influenced by each other, change in one process gets easily transferred to others and contributes to uncertainty in the process behaviour. Due to

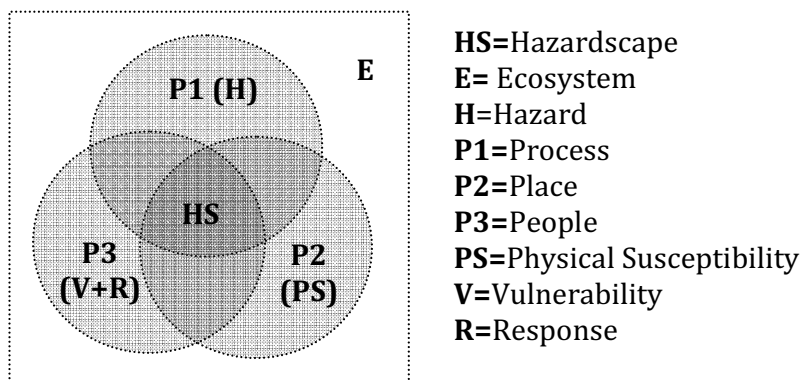

Fig. 2. A venn diagram of a hazardscape.

connectivity of various processes and the nested character of ecosystem, changes at the lower level (large scale) are brought by the small scale processes operating at the higher order. This explains hazard occurrences at the local level induced by the changes in global processes, such as climate change or economic recession.

\subsubsection{Characteristics}

Process, place and people are three key elements of a human ecological system where their interactions generate three key characteristics of a hazardscape i.e. hazards, physical susceptibility and human vulnerability (Fig. 2).

\subsubsection{Hazards}

The explanation of hazards has evolved from a concept of "acts of God" to an attribution as "environmental hazards", which exist at the interface of natural events and human use systems (Smith, 1992). Burton et al. (1978) called them negative resources, produced during the human-nature interaction. However, the depiction of humans and the environment as two different systems does not explain all hazards, especially those where such interactions are not visible at the same place. Therefore, they need to be defined in the context of ecosystem and the definition of hazards as "extreme fluctuations or deviations in environmental process (Smith, 1992), which could be dangerous to the community" and is more relevant in this sense. Hazards can occur through fluctuations in both biophysical and human environmental processes. However, biophysical hazards prove to be more 
dangerous than those derived from human changes, as most communities lack control measures for extreme fluctuations in biophysical processes which are often sudden and drastic in nature. Since all hazards vary in their frequency, duration, areal extent, speed of onset, spatial dispersion and temporal spacing (Burton et al., 1993, p. 34), they pose differential threat over space. Further, their multiple and variable combinations transmit variations in a hazardscape.

\subsubsection{Physical susceptibility}

Place represents the ecological relationship of the community with its environment. Each place holds individuality with its specific location and characteristics that could play a key role in turning an environmental process into a hazard by governing the process behaviours. Hewitt termed the physical susceptibility of a place as the "intervening conditions of disaster, which intervene between hazard and vulnerable structures" (Hewitt, 1997, p. 28). Cutter, Boruff and Shirley, put these under the category of biophysical vulnerability (Cutter et al., 2003, p. 243). However, to tag vulnerability to susceptibility is inaccurate in the sense that biophysical characteristics govern the behaviour of various environmental processes at a place, while variation in the degree of damage is a function of human vulnerability.

The physical characteristics contributing to the susceptibility of a place to hazards can be broadly classified into three categories i.e. location, natural biophysical characteristics and human modified biophysical conditions (Khan et al., 2012). The location (absolute or relative) of a place in the midst of various environmental processes often plays an overriding influence in hazard occurrence. The natural biophysical characteristics of a place including physiography, geology, hydrology, drainage or vegetation are mainly shaped by the biophysical processes. They not only make a place susceptible to different hazards but at times amplify hazards. Human-modified physical susceptibility is mainly the product of human processes and depends on the characteristics of the community that resides in a place. All three characteristics in combination result in varying susceptibilities to different hazards and produce diversity in hazardscapes.

\subsubsection{Vulnerability}

A hazardscape exists because of human vulnerability to various hazards. Vulnerability has grown into a complex concept with more than 25 definitions that explore the concept and methods for its systematic assessment (Birkmann, 2006, p. 11). The notion of vulnerability has expanded from incorporating concepts of internal risk factors to multidimensional vulnerability encompassing physical, social, economic, environmental and institutional features (Birkmann, 2006, p. 17). It is interpreted as "the characteristics of a person or group and their situation that influence their capacity to anticipate, cope with, resist and recover from the impact of a natural hazard" (Wisner et al., 2004, p. 11). The characteristics of population and their situation are influenced by both biophysical and human environmental processes. Whereas biophysical processes shape the basic socio-cultural norms related to livelihoods, food and other habits, the human processes define the systems of production and development along with other vulnerability factors such as entitlement, empowerment or political economy (Semple, 1911; Bohle, 2001; Wilhite, 1998; as cited in Birkmann 2006a, p. 120). It is important to consider these processes, as vulnerability is not all about the intrinsic characteristics of a population under normal environmental conditions, but about how these intrinsic characteristics would behave during an unanticipated change in environment (Patt et al., 2009, pp. 4-5).

All characteristics of a hazardscape are therefore interlinked and together they shape its character. The overall nature of hazardscape is however, more than the sum of its individual characteristics. It also reflects hazard awareness, perception, experience, response culture and trust among various response agencies, which govern both the impact and response to disasters.

\subsection{Hazardscape and response}

A hazardscape not only represents the context for hazard occurrence but also for response (Paton, 2006). Whereas all kinds of response intend to reduce hazards or modify the intensity of hazardscape, they are also shaped and influenced by the nature and characteristics of the hazardscape (Fig. 3).

Disaster management literature frequently classifies responses into four broad categories - mitigation, preparedness, emergency response and recovery, which are also referred to as 4Rs specifying reduction, readiness, response and recovery respectively (MCDEM, 2009; Godschalk and Brower, 1985). All kinds of responses (4Rs) start with minor adjustments either in behaviour or in the hazardscape. Their success over time helps communities to adopt them for the long term, and they become adaptations (Burton et al., 1993). IPCC (2007, p. 869), on the other hand, defines adaptation as "adjustments in natural or human systems in response to actual or expected climate stimuli or their effects, which moderates harm and exploits beneficial opportunities". A hazardscape represent the summation of all adjustments and adaptations opted for both present and future hazards (Paton, 2006).

Responses such as doing nothing, accepting loss, denial and ignorance of hazards reflect a limited or constrained capacity which increases vulnerability in a hazardscape and may lead to a disaster. In certain situations, even after making all adjustments and adaptations in a hazardscape, a disaster could occur either due to differences between actual and perceived hazards or because of the type of response chosen. The possibility of post-mitigation damage is embodied in the concept of residual risk (Beck, 1999). At times, residual risk from changes made in a local system for development 


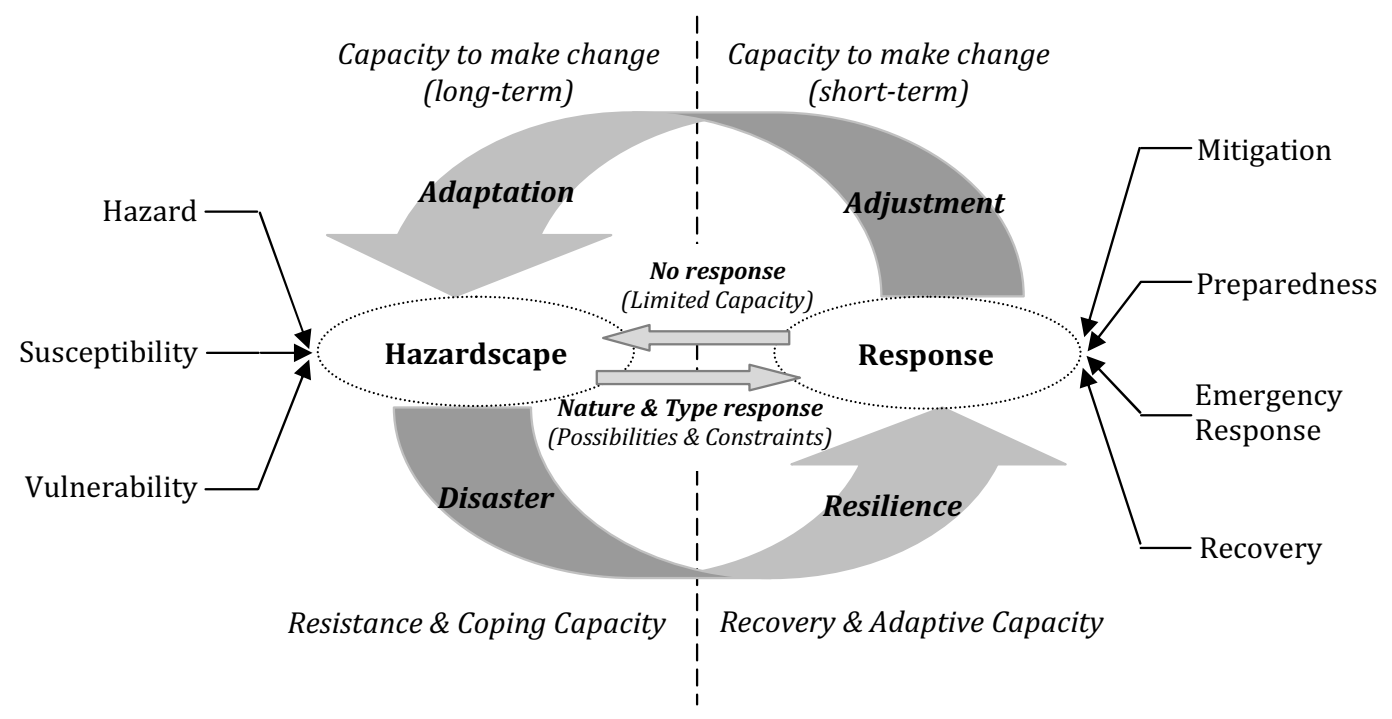

Fig. 3. Relationship between hazardscape and response.

surpasses awareness and coping capacity of the exposed community and could cause disaster. For example, deforestation for coffee plantation on terrace farming in Nicaragua made the local system more fragile to hurricane Mitch's heavy rain, which caused landslides, destroyed crops, infrastructure and villages in October 1998 (Comfort et al., 1999). After disaster, speed and extent of recovery, along with adaptation to the altered environmental conditions, marks the resilience of the community, which refers to the capability to regain original state (Paton, 2006). Disasters are also known to engender learning and actions for reducing future vulnerability and building resilience (Burton et al., 1993), and therefore, modify both response and hazardscape.

On the other side of this relationship, various characteristics of hazardscape including hazards, physical susceptibility and vulnerability influence the type of responses made, such as adjustment, adaptation, acceptance of loss or denial. Characteristics of hazards, such as magnitude, frequency and aerial extent determine the urgency of response in a hazardscape (Burton et al., 1993). These characteristics also influence the nature of mitigation measures adopted by a community. Speed of onset has a bearing on the preparedness and warning systems, and duration of hazard influences the type of measures to be taken. Similarly, spatial and temporal dispersion of a hazard are also visible in the response patterns, such as land use and cultural adaptations for timings of hazard response (Burton et al., 1993). Predictability and controllability of hazards also influence the level of preparedness and response of the local community. Physical susceptibility, on the other hand, not only governs the viability of engineering solutions, but may also influence the perception of hazards and related decision making for response (Khan, 2010; Khan et al., 2012). Mapping spatial variations in the physical and perceived susceptibility could provide an access to identify response gaps over space, and aid planning. Vulnerability further modifies response in many different ways. It is established that children, elderly and disabled people often have limited capacity to respond, while poor people in a community have fewer resources and options for hazard mitigation (Buckle et al., 2000; Cutter et al., 2003). It is found that economic reasons could prevent people from adopting adjustment measures and making use of available technology even if they are widely available (Lindell, 1997). Besides, hazard awareness, perception, experience, response culture and the level of trust among response agencies in a hazardscape also modify local response.

It can be said that overall in a physically active hazardscape which experiences recurrent damages from hazards, people are more aware and adopt a range of mitigation measures. On the other hand, a passive hazardscape that is occasionally affected by natural hazards generates attitudes resulting in slow or no response from people. Burton and Kates (1964) noted that dwellers in flood-prone areas often see floods as cyclic rather than random events and make adjustments accordingly (Leigh and Sim, 1983). In the Wellington Region, local preparedness for hazards, such as earthquakes and flooding is found to be very high due to their frequent occurrences, regular damages and government campaigns for active response (Khan, 2010). Another community survey shows that more than 70 per cent of the respondents in the Wellington Region had food, water and equipment supplies and nearly 30 per cent had emergency plan for hazards (Blakeley, 2006). In contrast, despite a predicted earthquake of 7 magnitude in a $50 \mathrm{yr}$ window from 1983-2033, very low preparedness for earthquakes is noted in Delhi, attributed to infrequent damaging events (Banerjee, 2011). UN Secretary General Kofi Annan noted that adaptations to climate change in most poorest countries of Africa 
are mainly survival-based (i.e. reactive adaptation) set in the context of poverty, disasters and environmental degradation (Cannon and Müller-Mahn, 2010). On the other hand, a significant shift in energy resources for climate change mitigation in Denmark denotes anticipatory adaptation (IPCC, 2001). These countries represent diverse hazardscapes where a sharp contrast in response is evident.

\subsection{Approach}

An understanding of various inter-linkages between human environment systems requires a holistic approach (Turner II et al., 2003). A holistic approach in a hazardscape framework subsumes an assessment of its various characteristics (hazards, physical susceptibility, vulnerability and overall hazardscape characteristics) in relation to the response practices and subsequent changes observed in space and time. In an ecosystem, the boundaries of hazardscapes are permeable that allow energy, matter and information to flow (Wessels, 2006). Changes in a hazardscape permeate through both local and global events in biophysical and human environments that not only modify hazards, physical susceptibility and vulnerability, but also response practices (Adger et al., 2009; Wessels, 2006). For example, the loss in Christchurch earthquake (2011) is estimated to be more than that of hurricane Katrina (2005) in terms of its economic impact on the national economy of New Zealand, modifying the local vulnerability and response investments at other locations in the country (AAP, 2011). At global scale, in 1995 Japan's Hanshins earthquake damage to the Port of Kobe (the sixth largest in the world) was felt across the globe due to its economic repercussions for other Asian economies that were dependent upon Japanese products and trade (Comfort et al., 1999). The impact of local and global events on response is evident in many cases. For example, in March 2011, about 34 per cent rise was noted in the sales of survival kits in Wellington city following the massive damage experienced in the earthquakes of Christchurch and Japan (Hall, 2011). Similarly, following the Indian Ocean Tsunami disaster in 2004, a tsunami siren was made operational in the Waitakere City of New Zealand (Brown, 2007). Many response practices also change because of the globalisation of knowledge, technology and practices. A holistic understanding of hazardscape could suggest new ways of response which may not be apparent through the study of individual hazardscape characteristics. Yet at the same time, the geographic connotation of hazardscape also retains the significance of a placebased approach, which is found to be more technically and economically viable for disaster reduction (Comfort et al., 1999).

\section{Gaps in institutional response practices}

Despite having diverse hazardscapes, a general trend can be witnessed in the hazards and disasters response at the institutional and national level in the world, which has evolved from a disaster specific reactive response until late 20th century to a risk based integrated emergency management in the 21st century (Britton, 2001). A formal acceptance of coordination and unification of efforts at the global level started with the United Nations declaration of the 1990s as an International Decade for Natural Disaster Reduction (IDNDR), which was followed by the International Strategy for Disaster Reduction (ISDR) in 1999 and Hyogo Framework for Action (HFA) from 2005 to 2015 (UNISDR, 2011). While strategies for disaster management still vary across nations, UN actions have contributed to a growing consensus in the world for how to respond to hazards and disasters. The World Summit on Sustainable Development (WSSD) (2002) concluded that an integrated, multi-hazard, inclusive approach to address vulnerability, risk assessment and disaster management, including prevention, mitigation, preparedness, response and recovery is an essential element of a safer world in the 21st century (O'Brien et al., 2006). International response to disasters provides evidence for the adoption of this approach but also shows gaps which have been brought forth in both the Yokohma Strategy for a Safer World (1994) and the Mid-term Review of the Hyogo Framework for Action (2011) (UNISDR, 2007, 2011). The following paragraphs show some gaps in common responses when assessed in relation to local hazardscapes.

\subsection{Integrated Emergency Management (IEM)}

An "integrated" disaster or emergency response is frequently emphasised in the disaster management literature (Wisner, 2011). This approach emerged in the United States in the early 1980s from where it diffused to other nations (Godschalk and Brower, 1985). It received a boost with the declaration of IDNDR, which by the end of the 1990s asked all countries to have fundamental outputs that would create a framework within which effective emergency management outcomes could be developed (Britton, 2001). It encouraged countries to undertake a comprehensive risk assessment of hazards integrated into national development plans, mitigation plans for long-term disaster prevention, preparedness, community awareness and ready access to warning systems by people who were most at risk at the global, national or local levels (Britton, 2001). From comprehensive risk assessment came the integrated emergency management (Britton, 2001). Some of the countries that follow this approach include the USA, UK, Australia, New Zealand, Thailand, India and China (Godschalk and Brower, 1985; Hills, 1998; Britton, 2001; Martin, 2001; Manuta et al., 2006; Shi et al., 2007; Khan, 2010). As Britton (2001) defines, the objectives of the integrated emergency management system include 
the formation of partnerships between different levels of resource owners, both vertically (between levels of government) and horizontally (between different agencies and the public-private sector). It also focuses on hazard analysis, capability maintenance, emergency response and recovery requirements (Britton, 2001). The Hyogo Framework for Action (HFA) specified integrated disaster reduction as the intrinsic element of United Nations Decade of Sustainable Development (2005-2015) and emphasised to integrate disaster risk reduction with development policies, poverty reduction, gender perspective, local culture and climate change (UNISDR, 2007). On a positive note, this approach encourages an organised and coordinated response from various agencies involved and directs focus to different aspects of response. At the ground level, such integration is rather an ambitious goal and gaps are frequently visible in recurrent disasters (Wisner, 2011).

Emergence of National Platforms from HFA in 73 nations has, despite enhanced interaction across different sectors for disaster risk reduction, noted total integration of response to be missing at different levels (UNISDR, 2011). Disaster management at the local level lacks unity and coherence promoted in the integrated response framework (Britton, 2006). In New Zealand, two key acts including Resource Management Act (RMA) (1991) and the Civil Defence and Emergency Management (CDEM) Act (2002) regulate the hazard response. Even though both acts advocate for an integrated hazard management, in practice a disconnect is noted throughout the country (Saunders et al., 2007). This is partly because the planning for hazard mitigation is mainly done by the district planners whose expertise and responsibilities lie in other fields (Godschalk and Brower, 1985). Civil Defence Officers, on the other hand, tend to have expertise in rescue and relief, and have less understanding of RMA (Britton, 1999; Saunders et al., 2007). The Wellington Regional Civil Defence and Emergency Management plan (2005) acknowledges and identifies needs and methods to overcome this gap, however, results are yet to be achieved (WREMG, 2005b). The primary survey with civil defence officers and district planners further confirmed this fact.

Similarly, integration of all response types (4Rs) are emphasised in planning, though not all of them are equally applied at the local level (MCDEM, 2009). For hazard mitigation, land use planning is applied (though at varied efficiency level) in many nations, but planning for recovery is found missing in most countries (Mitchell, 2006). In New Zealand, where there is a policy at the national level for disaster recovery, most city and district councils, as noted in the Wellington Region, lack detailed plans for recovery (Khan, 2010). Preparedness and emergency response, on the other hand, are noted to be actively planned and implemented at the regional and district level, but they do not consider different aspects of local hazardscape (Khan, 2010). Therefore despite conceptual acknowledgement, the response for $4 \mathrm{Rs}$ is not balanced at the local level.
The gap further expands among agencies responsible for mitigating existing risks and climate change adaptations to reduce future disasters. Taking the example of Indonesia, disaster risk reduction and climate change adaptation in the country are led by two different agencies named Badan Nasional Penanggulangan Bencana [BNPB] and Dewan Nasional Perubahan Iklim (DNPI) (Djalante et al., 2010). These institutes differ in their structural set up, funding mechanism and guidelines for operations, all of which have contributed to the limited progress for interlinking different aspects of disaster mitigation and climate change adaptation (Djalante et al., 2010). Similarly, examples can be noted in many other countries and India is one of them. An ever-increasing number of agencies with their specialised functions relating to disaster response and development make coordination and integration a difficult task.

\subsection{Multi- or all hazards approach}

Most of the current hazards and disaster management policies imply multi- or all hazards approach. At the global stage this shift occurred in the 1990s (Martin, 2001). In New Zealand, the Resource Management Act (1991) was a major step in this direction that emphasised all hazards management approach in land use planning (Grant, 2005). The HFA also emphasised a multi-hazard approach (UNISDR, 2007). While an increasing number of countries have agreed for multi-hazard response at the national level, gaps and shortcomings of this approach are prominent at the local level.

It is noted that a focus on multi- or all hazards tends to lead to a generic treatment of hazards. In the Wellington Region, New Zealand, most statutory acts and plans use an inclusive term for all-natural and man-made hazards, where there are significant differences in the number, type and intensity of these hazards at the local level. The Wellington Region in New Zealand is exposed to nine major natural hazards. While the Wellington Region Civil Defence and Emergency Management Plan (WRCDEM) recognises them all, the calculation and treatment of risk is generic at this level (WREMG, 2005b). The objectives and policies of the WRCDEM plan are based on various strategic issues linked with hazard reduction, readiness, response and recovery which are common for most hazards, and do not relate to the variations of hazards or risks at the local level. After the CDEM Act (2002), Territorial Local Authorities (TLAs) are no longer liable to make their own civil defence plans. Subsequently, the details of local hazard variations are missing in planning. In addition, the Standard Operation Procedures (SOPs), followed by the local civil defence organisations in the region for emergency response, are common for all emergencies without much of either hazard- or location-specific details (Khan, 2010). Although this brings a uniformity of hazard response across the region at a macro level, it fails to build standardization in terms of effectiveness of services at the local level. 
In the absence of a detailed guidance, both people and institutions tend to respond to hazards that pose high risk in the near future, which enhances the cumulative risks from unplanned hazards. This leads to multiple plans for a few hazards, while others are continuously neglected as noted in the Wellington Region (Khan, 2010). Most district plans are noted to have a detailed discussion, maps and rules for flooding and fault ruptures, a few of them discussed windstorm, tsunami, landslides and coastal hazards while none out of a total of six plans of the region mentioned drought, bushfire and volcanic ash fall, despite having physical susceptibility and vulnerability (Khan, 2010). Similar trends can be noted in most countries. In Thailand, the response to tsunami (despite high risk) has been compromised in the face of recurrent flooding and the impact was evident in the Indian tsunami 2004 (Manuta et al., 2006). Therefore, it is important that planning for response covers all hazards in a hazardscape.

\subsection{Risk governance}

Most of the current hazards and disasters plans are based on risk management approach (UNISDR, 2007; Amendola et al., 2008). Although this approach has been found successful in limiting the number of disasters, it has failed to stop disasters due to various reasons. Risk is understood as having both positive (opportunities) and negative (loss) dimensions, which are weighted against each other before decision making. As a result, risk-based planning compromises mitigation on the grounds of economic development, limited knowledge and time constraints. For example, the Wellington Region fault zone has been drawn (wide) and redrawn (slim) in the absence of "observed evidence" and possible effects on individual property prices (Council Committee, 2004; Stevens, 2005).

As risk-based planning addresses hazard of a selected magnitude, risk of disaster from the same hazard of greater magnitude prevails. The earthquake-proof building policy in New Zealand allows the construction of buildings with moderate protective measures in high-intensity earthquake zones (Grant, 2005). As a result, despite having a building code and its implementation, massive damage occurred in the 6.3 magnitude earthquake in Christchurch (2011) that required nearly 500 buildings to be replaced from its central business district (Woodford, 2011). Similarly, structural mitigation of flooding in New Zealand shows that despite numerous stop banks and dams, the exposed areas may still experience flooding (GWRC, 1998).

Frequently, risk management practices treat hazards that cause recurrent damage or disruption. They either overlook or accept risks from less frequent, high-magnitude hazards due to economic viability, structural inertia and lack of recognition of changing risks. This can be witnessed in various response measures taken at the local, regional and national level in New Zealand. The Wellington Region Civil Defence Emergency Management plan (2005) shows that while a high level of effort has been taken for high-frequency, low-magnitude hazard events, the opposite is true for lowfrequency, high-magnitude events (WREMG, 2005b). Therefore the possibility of disasters from unplanned events stands in most developed areas.

Also, in practice, treating risks primarily revolves around transferring risk or redistributing potential damage over space and time, rather than dealing with the root cause of vulnerability embedded in the socio-cultural and political context of power relations found dominant in developing countries (Lebel et al., 2006a; Wisner et al., 2004). It is mainly done by bringing changes in physical infrastructures and institutional responses, which helps those who need it less (Lebel, 2009). Diversifying the location of industries of high-economic investments from the central business district, and investing in structural flood protective measures are examples of risk redistribution over space and time (Lebel, 2009).

\subsection{Building resilience}

Another aspect of current disaster risk management is building resilience (UNISDR, 2007). The UNISDR (2001) adopted the term resilience and defined it as the capacity of a system, community or society to resist or to change in order for it to obtain an acceptable level in functioning and structure. This is determined by the degree to which the social system is capable of organising itself and the ability to increase its capacity for learning and adaptation, including the capacity to recover from disaster (O'Brien et al., 2006). The approach is readily taken by different nations and it gave a boost to literature on resilience (Paton, 2006; Buckle, 2006; Cutter et al., 2008). A resilience approach is also favoured over a vulnerability approach because the latter is observed to offer less scope for a proactive disaster response (Paton, 2006).

It has been noted that the key to enhance resilience is to reduce overall vulnerability including physical and socioeconomic vulnerability (Colten et al., 2008). However, in practice, as noted in New Zealand, the focus of building resilience is primarily directed towards reducing the vulnerability of infrastructure and services rather than people (Khan, 2010). By following the resilience approach, most acts in New Zealand for hazard mitigation primarily focus on maintaining emergency services and resource management rather than reducing human vulnerability (Khan, 2010). Even in the primary survey conducted in the Wellington Region, the civil defence officers and resource planners did not mention reducing human vulnerability when asked about methods of hazard reduction (Khan, 2010).

It is noted that vulnerability and resilience are not entirely a contrast but relate to each other (Zhou et al., 2010). WSSD (2002) revealed that the two-fold aim of disaster reduction strategies is to enable societies to be resilient, and ensure that development efforts do not increase vulnerability 
to hazard (O'Brien et al., 2006). The plans thus emphasise not increasing vulnerability rather than reducing it. For example, in New Zealand, district plans allow residents to build in hazard-prone areas if they do not increase the existing risks to hazards (Khan, 2010). This raises a few questions. Which measures have been taken to reduce existing vulnerability? How to deal with emerging vulnerabilities which are not predictable until development has taken place as most plans mainly talk about not increasing vulnerability through upcoming development? The situation is critical in developing countries where vulnerability is widespread. Kapur (2010) finds that in India nearly half of its population is vulnerable.

Planning only for resilience may also increase vulnerability in some cases. For example, in Thailand, rising economic growth has built resilience to a few hazards such as drought or food security, however, it has also produced a different kind of vulnerability by separating the very young and elderly population in the villages from working adults in the city (Rigg and Salamanca, 2009). This may result in greater vulnerability and poor response to disasters in rural areas. This is not to say that economic growth should not be promoted but it should also include planning for reducing vulnerability. In the urban context, where poor have migrated for work and income, nearly 30000 people of the Klong Toey community in Bangkok live on swamps and are vulnerable to land subsidence. Overcrowding, inaccessibility to clean water, absence of facilities for sewage and rubbish disposal, along with lack of education are other factors that contribute to their vulnerability (Lian, 1993). Besides, the country has nearly 366000 refugee and asylum seekers (IFRC, 2009), who may be vulnerable due to lack of awareness of hazards, lack of knowledge about response options and broken social support systems. If these characteristics are ignored and one just focuses on not letting it build further, the possibility of disasters prevails and increases over time. In Mexico, Lankao (2010) also notes that response is tilted towards providing assistance relief aimed at faster recovery for climate-induced disasters, rather than providing support for mitigating factors responsible for vulnerability of those who are most vulnerable (Lankao, 2010). This helps less as it only covers up the vulnerability which gets exposed during disasters. The relief received is then either used to survive or build the previous standards rather than moving forward for a sustainable development. There is a need to bring a specific focus on reducing human vulnerability in addition to building resilience.

One important distinction between the two phenomena is that vulnerability is a pre-event characteristic of the community that makes it liable to suffer from a disaster, while resilience is a post-event characteristic that helps the community to cope and recover from the disaster (Cutter et al., 2008). Planning for resilience therefore, also requires an understanding of vulnerability, particularly in a changing hazardscape through climate change. Vulnerability is dynamic and it changes in both space and time (Cutter and Finch,
2008; Khan, 2010). Khan (2010) shows variations in the nature and type of vulnerability throughout the Wellington Region which are not planned for the hazards and emergency management of the region. An understanding of the existence and cause of vulnerability over space provides an opportunity to reduce it and strengthen local resilience.

\subsection{Top-down approach for risk and emergency management}

Integrated risk or emergency management also has a topdown approach, whereby the response is channelled by various institutional bodies and is applied through defined administrative channels in particular boundaries. The drawbacks of a centralised top-down approach has been revealed in the vulnerability to numerous disasters in the former Soviet Union, Russia, China and Vietnam (Porfiriev, 2006). A centralised institutional response to the Indian ocean tsunami disaster (2004) delayed the compensation for fishermen communities in the southern Thailand, who not only suffered greater damages from the tsunami but faced numerous problems in recovery because of bureaucratic constraints in communicating their needs across hierarchical administrative setup (Lebel et al., 2006a).

A top-down approach frequently results in application of common mitigation measures, such as building codes or dams across diverse hazardscapes that may increase local vulnerability. "Universal" design and construction standards for buildings are found to be a significant cause of damage in the 1995 Neftegorsk earthquake in the Soviet Union (Porfiriev, 2006). The conventional institutional response to disasters and climate change often ignore local variations in hazard perception and response of people which are "culturally" shaped (Cannon and Müller-Mahn, 2010). In Thailand, before the arrival of structural mitigation, flooding was deeply connected to the local culture. The community had adapted to the seasonal flooding and used to celebrate it with songs and dance (Manuta et al., 2006). The placement of structural measures, such as stop banks or dams, made the community vulnerable to disaster by disrupting the local ecological relationship of the community with environment, and exposing them to flooding of greater magnitude (Manuta et al., 2006). Superimposing universal scientific rationality over varied local rationalities by discounting gaps thus increases vulnerability and deters adaptation (Cannon and Müller-Mahn, 2010).

The top-down approach has also been criticised for not having a community viewpoint and therefore not being able to meet their expectations. It has been repeatedly argued that the viewpoints of the vulnerable groups including women, minorities, disabled, elderly or children should be part of the planning for recovery, prevention and mitigation activities (Comfort et al., 1999). Besides, the top-down approach frequently discounts local knowledge and practices that have built resilience in the past. Local knowledge, 
mainly indigenous knowledge, is based on a long-term ecological relationship, and incorporates traditional methods and practices to avoid disaster. The survival of the Moken community (sea gypsies) in the Indian ocean tsunami illustrates the significance of the local knowledge for disaster response (Manuta et al., 2005).

The failures of a top-down approach in dealing with disasters have led the recent literature to focus on a bottom-up or community-based approach (Wisner, 2006; Van Aalst et al., 2008). The bottom-up approach provides many advantages, such as enhancing integration within a community, building hazard awareness and fulfilling a need for a collective response for disasters. In developing countries such as India and Bangladesh, the community-based approach has been found to be effective in dealing with many severe hazards including flooding and droughts (Jain, 2000; Shaw, 2006). A community-based risk assessment in Indonesia has also shown that it enhances the decision makers' awareness of disaster risk drivers, enables building local coping capacities rather than relief dependence and a better gender equity which modifies both vulnerability and response (Bollin and Hidajat, 2006).

The HFA (2005-2015) also asked for an integration of national and local activities for disaster reduction, however, at the local level activities were either found to be not linked to a wider disaster reduction system, or the effective decentralisation were limited to high income groups and Caribbean countries (UNISDR, 2011). In countries that have adopted decentralisation of response by considering the value of bottom-up approach, sustenance of this practice is challenging. Often, a major shock or disaster is sufficient enough to reintroduce an authoritative response. The establishment of the Department of Homeland Security after the 9/11 terrorist attacks (2001) and emphasis on centralised response after Hurricane Katrina (2005) in USA, as well as the establishment of The Canterbury Earthquake Response and Recovery Act (2010) are a few examples (Porfiriev, 2006; Mitchell, 2006; Bennett, 2010). This reactive recovery response focuses on bringing a pre-disaster normality, rather than building for a new long-term sustainability. Since under the influence of global climate change many changes are likely to be drastic and beyond traditional expectations, it is important to link both institutional top-down and communitybased bottom-up approaches by having a holistic strategy that merges both scientific and traditional knowledge (Lebel et al., 2006b).

\subsection{A holistic approach}

The HFA emphasises a holistic approach towards disaster risk reduction by promoting and supporting dialogue, information exchange and coordination among early warning, disaster risk reduction, disaster response, development and other relevant agencies and institutions at all levels (UNISDR, 2007). The mid-term review of HFA, however, finds that the suggested response is not applied in a holistic manner (UNISDR, 2011). If assessed by using the hazardscape framework for holistic approach, it can also be drawn here that there is an excessive emphasis on institutional response and coordination rather than reducing the causes of disaster sourced in a hazardscape (Hills, 1998). The CDEM plan of the Wellington Region identifies a number of organisations, their role and responsibilities for 4Rs (WREMG, 2005a), but it does not specify local variations in its hazardscape including hazards characteristics, biophysical susceptibility, vulnerability or its dynamic character. This leads to a partial treatment of hazards, because frequently response either focuses on any particular hazard characteristics or area. In Thailand the response to flooding is primarily based on the hazard characteristics (such as frequency, intensity or spatial dispersion), landslide response revolves around mapping places' susceptibility and the vulnerability of coastal communities to the tsunami was dealt with only after disaster occurrence (Phien-Wej et al., 1993; Manuta et al., 2006; Lebel et al., 2006a; ADPC, 2006). The response based on individual characteristics for specific hazards fails to treat other contributing factors, and subsequently, hazards continue to persist and may cause damage. This is evident in the failures of structural measures taken for flooding in Thailand, which cause regular damage despite active planning for the hazard (Manuta et al., 2006).

Further, a hazardscape varies in time with socio-economic changes, which are likely to be exacerbated by global climate change. Inadequate consideration of changing hazardscapes through climate change can be noted in most emergency management planning. Integrating disaster mitigation and climate change adaptation for planning and application is still in its early stages, and in most countries the two remain separate. The comprehensive disaster management programme of Bangladesh includes climate change impacts, but it can be marked as an exception rather than rule (Djalante et al., 2010). Even though efforts are made to interlink disaster response with climate change in various countries, a holistic approach that combines the two for emergency response is missing. The response, such as rescue or recovery, is often defined in a rigid sense, which offers less flexibility to accommodate future uncertainties in the nature of hazards and response required (Hills, 1998). They are based on the assumption that disasters follow a linear path rather than having unpredictable and erratic behaviour that may involve conflicts in various scale issues or discontinuities in response from people and institutions (Hills, 1998). The response, therefore, needs to be defined along the lines of hazardscape rather than simply focusing on response practices.

\section{Conclusions}

It is known that despite enhanced knowledge of hazards and consensus on methods to deal with them, losses in disasters 
are increasing (White et al., 2001). Most disasters are still labelled as "surprise events", but they seem inevitable when responses (4Rs) are assessed in relation to the local hazardscapes. In the current planning practices, many aspects of the local hazardscapes go unnoticed and therefore hazard mitigation fails to achieve its goal. A few shortcomings of the widely accepted integrated emergency management are noted in its excessive focus on response mechanism, risk governance, disconnect between top-down and bottomup approaches, and a preference for resilience over reducing local vulnerability. A holistic view of the hazardscape could contribute to the understanding of both causes of disasters and gaps in the ongoing response practices, and therefore it could lead to more effective planning. Its geographical connotation also retains the value of place-based knowledge while using the ecosystem framework to observe changes at different levels and scales.

\section{Abbreviations:}

\begin{tabular}{|c|c|}
\hline NDR: & $\begin{array}{l}\text { International Decade for Natural Disaster } \\
\text { Reduction }\end{array}$ \\
\hline JNISDR: & $\begin{array}{l}\text { United Nations International Strategy for } \\
\text { Disaster Reduction. }\end{array}$ \\
\hline WSSD: & World Summit on Sustainable Development \\
\hline HFA: & Hyogo Framework for Action \\
\hline BNPB: & Badan Nasional Penanggulangan Bencana \\
\hline DNPI: & Dewan Nasional Perubahan Iklim \\
\hline MCDEM: & $\begin{array}{l}\text { Ministry of Civil Defence and Emergency } \\
\text { Management }\end{array}$ \\
\hline WREMG: & $\begin{array}{l}\text { Wellington Region Emergency Management } \\
\text { Group }\end{array}$ \\
\hline RMA: & Resource Management Act \\
\hline CDEM & Civil Defence and Emergency Management \\
\hline 4Rs: & $\begin{array}{l}\text { Reduction, Readiness, Response and } \\
\text { Recovery }\end{array}$ \\
\hline
\end{tabular}

Acknowledgements. The author is grateful to the New Zealand Climate Change Research Institute, Victoria University of Wellington for funding the preparation of this research paper. The author would like to acknowledge Martin Manning and Judy Lawrence for their support and constructive comments on this paper, and Kanchan Gandhi for her meaningful comments and last-minute proofreading. The author also thanks Michael J. Crozier for her $\mathrm{PhD}$ guidance that enabled the development of hazardscape as a conceptual framework. She is also thankful to the reviewers who provided useful comments that helped to improve this paper.

Edited by: T. Glade

Reviewed by: S. Reese, K. Sudmeier-Rieux, and one anonymous referee

\section{References}

Adger, W. N.: Vulnerability, Global Environ. Change, 16, 268-281, 2006.

Adger, W. N., Eakin, H., and Winkels, A.: Nested and teleconnected vulnerabilities to environmental change, Front. Ecol. Environ., 7, 150-157, doi:10.1890/070148, 2009.

ADPC: Rapid Assessment: Flashflood and Landslide Disaster in the Provinces of Uttaradit and Sukhothai Northern Thailand, Asian Disaster Preparedness Center, Bangkok, 2006.

Amendola, A., Linnerooth-Bayer, J., Okada, N., and Shi, P.: Towards integrated disaster risk management: case studies and trends from Asia, Nat. Hazards, 44, 163-168, doi:10.1007/s11069-007-9152-z, 2008.

Barry, J.: Environment and Social Theory, Second Edition, Routledge, London, at-a-glance: Countries hit http://news.bbc.co.uk/ 2/hi/asia-pacific/4126019.stm, (last access: 22 December 2005), 2007.

Birkmann, J.: Measuring Vulnerability to Promote DisasterResilient Societies: Conceptual Frameworks and Definitions, in: Measuring Vulnerability to Natural Hazards: Towards Disaster Resilient Societies, edited by: Birkmann, J., United Nations University Press, Tokyo, 9-54, 2006.

Blakeley, R.: Community Preparedness Survey Results, Greater Wellington Regional Council, Wellington, http://www.gw.govt.nz/council-reports/pdfs $\% 5$ Creportdocs\% 5C2006_601_1_Report.pdf, 2006.

Bohle, H.: Vulnerability and Criticality: Perspectives from Social Geography, IHDP Update: Newsletter of the International Human Dimensions Programme on Global Environmental Change, 2, 1-7, 2001.

Bollin, C. and Hidajat, R.: Community-based Risk Index: Pilot Implementation in Indonesia, in: Measuring Vulnerability to Natural Hazards: Towards Disaster Resilient Societies, edited by: Birkmann, J., United Nations University, Tokyo, 2006.

Britton, N.: Whither the Emergency Manager?, Int. J. Mass Emergencies Disasters, 17, 223-235, 1999.

Britton, N.: A New Emergency Management for the Millenium?, Aust. J. Emerg. Manage., 16, 44-54, 2001.

Britton, N.: National Planning and Response: National Systems, in: Handbook of Disaster Research, edited by: Rodríguez, H., Quarantelli, E. L., and Dynes, R. R., Springer, New York, 347-367, 2006.

Buckle, P., Mars, G., and Smale, S.: New approaches to assessing vulnerability and resilience, Aust. J. Emerg. Manage., 15, 8-14, 2000.

Buckle, P.: Assessing Social Resilience, in: Disaster Resilience : An Integrated Approach, edited by: Paton, D. and Johnston, D., Charles Thomas, Springfield, USA, 88-104, 2006.

Burton, I. and Kates, R. W.: The Floodplain and the Seashore: A Comparative Analysis of Hazard-Zone Occupance, Geogr. Rev., 54, 366-385, 1964.

Burton, I., Kates, R. W., and White, G. F.: The Environment as Hazard, Oxford University Press, New York, 1978.

Burton, I., Kates, R. W., and White, G. F.: The Environment as Hazard, Second ed., The Guilford Press, New York, 290 pp., 1993.

Cannon, T. and Müller-Mahn, D.: Vulnerability, resilience and development discourses in context of climate change, Nat. Hazards, 55, 621-635, doi:10.1007/s11069-010-9499-4, 2010. 
Catton, W. R. J.: Foundation of Human Ecology, Sociological Perspectives, 37, 75-95, 1994.

Chorley, R. J.: Geography as Human Ecology, in: Directions in Geograpy, edited by: Chorley, R. J., Methuen, London, 1973.

Clary, B. B.: The Evolution and Structure of Natural Hazard Policies, Public Administration Review, Special Issue: Emergency Management: A Challenge for Public Administration, 45, 20-28, 1985.

Colten, C. E., Kates, R. W., and Laska, S. B.: Community Resilience: Lessons from New Orlieans and Hurricane Katrina, Community and Regional Resilience Initiative, Oak Ridge, 2008.

Comfort, L., Wisner, B., Cutter, S., Pulwarty, R., Hewitt, K., OliverSmith, A., Wiener, J., Fordham, M., Peacock, W., and Krimgold, F.: Reframing disaster policy: the global evolution of vulnerable communities, Environ. Hazards, 1, 39-44, 1999.

Corson, M. W.: Hazardscapes in Reunified Germany, Environ. Hazards, 1, 57-68, 1999.

Cutter, S. L., Mitchell, J. T., and Scott, M. S.: Revealing the Vulnerability of People and Places: A Case Study of Georgetown County, South Carolina, Ann. Assoc. Am. Geogr., 90, 713-737, 2000.

Cutter, S. L., Boruff, B. J., and Shirley, W. L.: Social Vulnerability to Environmental Hazards, Soc. Sci. Quart., 84, 242-261, 2003.

Cutter, S. L., Barnes, L., Berry, M., Burton, C., Evans, E., Tate, E., and Webb, J.: A place-based model for understanding community resilience to natural disasters, Global Environ. Change, 18, 598-606, 2008.

Cutter, S. L. and Finch, C.: Temporal and spatial changes in social vulnerability to natural hazards, PNAS, 105, 2301-2306, 2008.

CRED: EM-DAT: The International Disaster Database. Data version: v12.07. Centre for Research on the Epidemiology of Disasters, 8 April 2012.

Djalante, R., Halder, S. R., Mulyasari, F., and Khan, S.: Linking Disaster Risk Reduction and Climate Change Adaptation: comparing experiences from developed and developing countries, in: SOURCE: "Studies of the University: Research, Counsel, Education”, edited by: Buckle, P., Birkmann, J., and Setiadi, N. J., Bonn, 102-116, 2010.

Ericksen, N. J.: Creating flood disasters? : New Zealand's need for a new approach to urban flood hazard, Published for the National Water and Soil Conservation Authority by the Water and Soil Directorate, Ministry of Works and Development, Wellington, N.Z., 322 pp., 1986.

Glade, T. Anderson, M., and Crozier, M. J.: Landslide Hazard and Risk, J. Wiley, Chichester, 824, 2005

Godschalk, D. R. and Brower, D. J.: Mitigation Strategies and Integrated Emergency Management, Public Administration Review. Special Issue: Emergency Management: A Challenge for Public Administration, 45, 64-71, 1985.

Grant, H.: Natural Hazards: Background Report, Greater Wellington Regional Council, Wellington, 79 pp., 2005.

Gray, W.: Research for Resilience, Tephra, 32-38, 2001.

GWRC: Otaki Floodplain Management Plan: The Community's Plan for the Otaki River and its Environment, Greater Wellington Regional Council, Wellington, 109 pp., 1998.

Hawley, A. H.: Human Ecology - A Theoretical Essay, The University of Chicago Press, Chicago, 176 pp., 1986.

Hewitt, K.: Regions of Risk: A Geographical Introduction to Disasters, Longman, Essex, UK, 389 pp., 1997.
Hills, A.: Seduced by Recovery: The Consequences of Misunderstanding Disaster, J. Contingencies Crisis Manage., 6, 162-170, 1998.

IFRC: World Disaster Report 2009, International Federation of Red Cross and Red Crescent Society, Geneva, 2009.

Jain, N. K.: Floods in South Asian Context: Critical Reflections on the International Decade and Local Community Participation in Flood Disaster Reduction, in: Floods, edited by: Parker, D. J., Routledge, New York, 255-259, 2000.

Kapur, A.: Vulnerable India: A Geographical Study of Disasters, Sage Publication, New Delhi, 269 pp., 2010.

Kates, R. W.: Natural Hazard in Human Ecological Perspective: Hypothesis and Models, Econom. Geogr., 47, 438-451, 1971.

Khan, S.: A Geographical Assessment of Hazardscape of Wellington Region: Influences on Intra-regional Response, $\mathrm{PhD}$, School of Geography, Environment and Earth Sciences, Victoria University of Wellington, Wellington, 421 pp., 2010.

Khan, S., Crozier, M. J., and Kennedy, D.: Influences of place characteristics on hazards, perception and response: a case study of the hazardscape of the Wellington Region, New Zealand, Nat. Hazards, doi:10.1007/s11069-012-0091-y, 2012.

Lankao, P. R.: Water in Mexico City: what will climate changebring to its history of water-related hazards and vulnerability?, Environ. Urban., 22, 157-178, doi:10.1177/0956247809362636, 2010.

Lebel, L., Nikitina, E., and Manuta, J.: Flood Disaster Risk Management in Asia: An Institutional and Political Perspective, Science and Culture, 72, 2-9, 2006a.

Lebel, L., Nikitina, E., Vladimir, K., and Manuta, J.: Assessing Institutionalised Capacities and Practices to Reduce the Risks of Flood Disaster, in: Measuring Vulnerability to Natural Hazards: Towards Disaster Resilient Societies, edited by: Birkmann, J., University Nations University Press, Tokyo, 2006b.

Leigh, C. H. and Sim, L. K.: Attitude and Adjustments to the Flood Hazard in a Mixed Ethnic Community in Malacca Town, Peninsular Malaysia, Singapore J. Trop. Geogr., 4, 40-52, 1983.

Lian, F. J.: On Threatened People, in: South-East Asia's Environmental Future: The Search for Sustainability, edited by: Brookfield, H. and Byron, Y., United Nations University Press, Tokyo, 322-337, 1993.

Lindell, M. K.: Adoption and Implementation of Hazard Adjustment, Int. J. Mass Emerg. Disasters, 15, 327-453 1997.

Manuta, J., Khrutmuang, S., Huaisai, D., and Lebel, L.: Institutionalised Incapacities and Practices in Flood Disaster Management in Thailand, Sci. Cult., 72, 10-22, 2006.

Manuta, J. B., Khrutmuang, S., and Lebel, L.: The Politics of Recovery: Post-Asian Tsunami Reconstruction in Southern Thailand, Trop. Coasts, 12, 30-39, 2005.

Martin, B.: Are disaster management concepts relevant in developing countries?: A case of the 1999-2000 Mozambican floods, Aust. J. Emerg. Manage., 16, 25-32, 2001.

Mileti, D. S.: Disasters by design : A reassessment of natural hazards in the United States, Joseph Henry Press, Washington, 1999.

Mitchell, J. K.: The primacy of partnership: Scoping a new national disaster recovery policy, The ANNALS of the American Academy of Political and Social Sciences, 604, 228-255, doi:10.1177/0002716205286044, 2006.

Mustafa, D.: The Production of an Urban Hazardscape in Pakistan: Modernity, Vulnerability, and the Range of Choice, 
Ann. Assoc. Am. Geogr., 95, 566-586, doi:10.1111/j.14678306.2005.00475.x, 2005.

O'Brien, G., O'Keefe, P., Rose, J., and Wisner, B.: Climate change and disaster management Disasters, 30, 64-80, doi:10.1111/j.1467-9523.2006.00307.x, 2006.

ODESC: National Hazardscape Report, Official's Committee for Domestic \& External Security, Wellington, 140 pp., 2007.

Paton, D.: Disaster Resilience: Building Capacity to Co-exist with Natural Hazards and Their Consequences, in: Disaster Resilience: An Integrated Approach, edited by: Thomas, C. C., Paton, D., and Johnston, D., Springfied, USA, 3-10, 2006.

Patt, A. G., Schroter, D., Vega-Leinert, A. C. D. L., and Klein, R. J. T.: Vulnerability Research and Assessment to Support Adaptation and Mitigation: Common Themes from the Diversity of Approaches, in: Assessing Vulnerability to Global Environmental Change: Making Research Useful for Adaptation, Decision Making and Policy, edited by: Patt, A. G., Schroter, D., Vega-Leinert, A. C. D. L., and Klein, R. J. T., Earthscan, London, 2009.

Pearce, L.: Disaster Management and Community Planning, and Public Participation: How to Achieve Sustainable Hazard Mitigation, Nat. Hazards, 28, 211-228, doi:10.1023/a:1022917721797, 2003.

Phien-Wej, N., Nutalaya, P., Aung, Z., and Zhibin, T.: Catastrophic Landslides and Debris Flows in Thailand, Bull. Int. Assoc. Eng. Geol., 48, 93-100, 1993.

Porfiriev, B. N.: Disasters and Crisis Management in Transitional Societies: Commonalities and Peculiarities, in: Handbook of Disaster Research, edited by: Rodríguez, H., Quarantelli, E. L., and Dynes, R. R., Springer, New York, 368-387, 2006.

Reese, S., Bell, R., King, A., and Team, R.: Riskscape: a new tool for comparing risk from natural hazards Water and Atmosphere, 15, 24-25, 2007.

Rigg, J., and Salamanca, A.: Managing risk and vulnerability in Asia: A (re)study from Thailand, 1982-83 and 2008, Asia Pac Viewpoint, 50, 255-270, doi:10.1111/j.14678373.2009.01399.x, 2009.

Saunders, W., Forsyth, J., Johnston, D., and Becker, J.: Strengthening Linkages Between Land-use Planning and Emergency Management in New Zealand, The Australian Journal of Emergency Management, 22, 36-43, 2007.

Shaw, R.: Critical Issues of Community Based Flooding Mitigation: Examples from Bangladesh and Vietnam, Science and Culture, 72, 62-71, 2006.

Smith, K.: Environmental Hazards: Assessing Risk and Reducing Disaster, 1st ed., Routledge, London, 324 pp., 1992.

Stevens, G.: The Totara Park Planning Tribunal 1964: Living With Active Fault, GSNZ Newsletter, 137, 26-31, 2005.

Tansley, A. G.: The Use and Abuse of Vegetational Concepts and Terms, Ecology, 16, 284-307, 1935.

Tobin, G. A. and Montz, B. E.: Natural Hazards: Explanation and Integration, The Guilford Press, New York, 1997.

Turner II, B. L., Kasperson, R., Matson, P. A., McCarthy, J. J., Corell, R. W., Christensen, L., Eckley, N., Kasperson, J. X., Luers, A., Martello, M. L., Polsky, C., Pulsipher, A., and Schiller, A.: A framework for vulnerability analysis in sustainability science, PNAS, 100, 8074-8079, doi:10.1073/pnas.1231335100 2003.
UNISDR: Hyogo Framework for Action 2005-2015: Building the Resilience of Nations and Communities to Disasters, United Nations, Geneva, 24 pp., 2007.

UNISDR: 2009 UNISDR Terminology on Disaster Risk Reduction United Nations Geneva, 2009a.

UNISDR: Global assessment report on disaster risk reduction 2009: risk and poverty in a changing climate, United Nations, Geneva, 2009b.

UNISDR: Hyogo Framework for Action 2005-2015: Building the Resilience of Nations and Communities to Disasters: Mid-term Review 2010-2011, United Nations, Geneva, 2011.

Van Aalst, M. K., Cannon, T., and Burton, I.: Community level adaptation to climate change: The potential role of participatory community risk assessment, Glob. Environ. Change, 18, 165179, 2008.

Wessels, T.: The Myth of Progress: Towards a Sustainable Future, University Press of New England, London, 164 pp., 2006.

White, G. F., Kates, R. W., and Burton, I.: Knowing better and losing even more: the use of knowledge in hazards management, Glob. Environ. Change Part B: Environmental Hazards, 3, 8192, 2001.

Whitmarsh, L. E.: A Study of Public Understanding of and Response to Climate Change in the South of England, $\mathrm{PhD}$, Department of Psychology, University of Bath, UK, 427 pp., 2005.

Wisner, B., Blaikie, P., Cannon, T., and Davis, I. E.: At risk: Natural hazards, people's vulnerability and disasters, Second ed., Routledge, London, 2004.

Wisner, B.: Self-assessment of Coping Capacity: Participatory, Proactive and Qualitative Engagement of Communities in Their Own Risk Management, in: Measuring Vulnerability to Natural Hazards: Towards Disaster Resilient Societies, edited by: Birkmann, J., United Nations Press, Tokyo, 2006.

Wisner, B.: Are We There Yet? Reflections on Integrated Disaster Risk Management after Ten Years, J. Integrated Disaster Risk Manag., 1, 1-14, doi:10.5595/idrim.2011.0015, 2011.

World News Atlas: World Disasters Timeline, http://www. mapreport.com/subtopics/d.html, 23 September 2011.

Understanding the Christchurch earthquake: Building damage http: //keithwoodford.wordpress.com, last access: 26 March 2011, 2011.

World Disasters Timeline, last access: 23 September 2011, 2011.

WREMG: Hazard and Risk Analysis for the Wellington Region Civil Defence Emergency Management Group Plan, Wellington Region Emergency Management Group, Wellington, 2005a.

WREMG: The Wellington Region Civil Defence Emergency Management Group Plan, Wellington Region Emergency Management Group, Riskscape, Wellington, 2005b.

Zhou, H., Wang, J. A., Wan, J., and Jia, H.: Resilience to natural hazards: a geographic perspective, Nat. Hazards, 53, 21-41, doi:10.1007/s11069-009-9407-y, 2010. 